\title{
A NON GREEN'S FUNCTION APPROACH TO FRACTIONAL LYAPUNOV-TYPE INEQUALITIES WITH APPLICATIONS TO MULTIVARIATE DOMAINS
}

\author{
Sougata Dhar and Jessica Stewart Kelly
}

\begin{abstract}
We derive Lyapunov-type inequalities for certain fractional differential equations of order $\alpha$, where $1<\alpha \leqslant 2$ or $2<\alpha \leqslant 3$. The methods used within rely on considering the maximum value of a nontrivial solution in a given interval as opposed to traditional methods which utilize the Green's function. This particular method provides versatility and can be applied to other fractional boundary value problems where the Green's function is inaccessible. Furthermore, we demonstrate how the inequalities may be extended to fractional multivariate equations in both the left and right-fractional cases.
\end{abstract}

Mathematics subject classification (2010): 34A08, 34A40, 26A33, $26 \mathrm{~B} 05$.

Keywords and phrases: Fractional differential equations, Lyapunov-type inequalities, non Green's function method, multivariate domains.

\section{REFERENCES}

[1] G. A. Anastassiou, Multivariate Lyapunov inequalities, Appl. Math. Lett., 24 (2011), 2167-2171.

[2] R. C. BRown AND D. B. Hilton, Opial's inequality and oscillation of second-order equations, Proc. Amer. Math. Soc., 125 (1997), 1123-1129.

[3] G. Borg, On a Liapunoff criterion of stability, Amer. J. Math., 71 (1949), 67-70.

[4] S. DHAR AND Q. KONG, Liapunov-type inequalities for third-order half-linear equations and applications to boundary value problems, Nonlin. Anal., 110 (2014), 170-181.

[5] S. DHAR AND Q. KONG, Lyapunov-type inequalities for higher order half-linear differential equations, Appl. Math. Comput., 273 (2016), 114-124.

[6] S. DHAR AND Q. KONG, Lyapunov-type inequalities for third-order linear differential equations, Math. Inequal. Appl., 19 (2016), 297-312.

[7] S. DhaR, Q. Kong AND M. MCCABE, Fractional boundary value problems and Lyapunov-type inequalities with fractional integral boundary conditions, Electron. J. Qual. Theory Differ. Equ., 2016, no. $43,1-16$.

[8] S. DhaR AND Q. Kong, Lyapunov-type inequalities for odd order linear differential equations, Submitted.

[9] R. A. C. FERREIRA, On a Lyapunov-type inequality and the zeros of a certain Mittag-Leffler function, J. Math. Anal. Appl., 412 (2014), 1058-1063.

[10] R. A. C. FERREIRA, A Lyapunov-type inequality for a fractional boundary value problem, Fract. Calc. Appl. Anal., 16 (2013), 978-984.

[11] E. I. Fredholm, Sur une classe d'equations fonctionnelles, Acta Math., 27 (1903), 365-390.

[12] J. R. Graef, R. Mahmoud, S. H. SAKer And E. Tunc, Some New Lyapunov-type Inequalities for Third Order Differential Equations, Comm. Appl. Nonlinear Anal., 22 (2015), no. 2, 1-16.

[13] P. Hartman, Ordinary Differential Equations, Wiley, New York, 1964, and Birkhauser, Boston 1982.

[14] B. J. HARRIS AND Q. KONG, On the oscillation of differential equations with an oscillatory coefficient, Transactions of the AMS, 347 (1995), 1831-1839.

[15] M. Hashizume, Minimization problem related to a Lyapunov inequality, J. Math. Anal. Appl. 432 (2015), 517-530. 
[16] M. JLELI AND B. SAMET, Lyapunov-type inequalities for fractional boundary value problems, Elec. J. Diff. Eq., 2015 (2015), 1-11.

[17] M. JLELI AND B. SAMET, Lyapunov-type inequalities for a fractional differential equation with mixed boundary conditions, Math. Inequal. Appl., 18 (2015), 443-451.

[18] M. JLELI, M. KIRANE, B. SAMET, Lyapunov-type inequalities for fractional partial differential equations, Appl. Math. Lett., 66 (2017), 30-39.

[19] M. Jleli, L. Ragoub, B. SAmet, A Lyapunov-type inequality for a fractional differential equation under a Robin boundary condition, J. Funct. Spaces, 2015, Art. ID 468536, 5 pp.

[20] A. A. Kilbas, H. M. Srivastava And J. J. Trujilo, Theory and Applications of Fractional Differential Equations, North-Holland Mathematical Studies 204, Elsevier, Amsterdam 2006.

[21] M. K. Kwong, On Lyapunov inequality for disfocality, J. Math. Anal. Appl., 83 (1981), 486-494.

[22] A. M. Liapunov, Probleme general de la stabilite du mouvement, Ann. Math Stud., 17 (1947), 203 474.

[23] P. L. De NAPOli And J. P. Pinasco, Lyapunov-type inequalities for partial differential equations, J. Funct. Anal., 270 (2016), 1995-2018.

[24] D. O'REGAN AND B. SAMET, Lyapunov-type inequalities for a class of fractional differential equations, J. Ineq. Appl., 2015, 2015:247.

[25] N. Parhi And S. PANIGRAhi, On Liapunov-type inequality for third-order differential equations, J. Math. Anal. Appl. 233 (1999), 445-460.

[26] N. PARHI AND S. PANIGRAHI, Liapunov-type inequality for higher order differential equations, Math. Slovaca 52 (2002), 31-46.

[27] J. P. PINASCO, Lyapunov-type inequalities with Applications to Eigenvalue Problems, Springer, 2010.

[28] J. RoNG AND C. BAI, Lyapunov-type inequality for a fractional differential equation with fractional boundary conditions, Adv. Diff. Eq., 2015, 2015:82.

[29] S. G. Samko, A. A. Kilbas And O. I. Marichev, Fractional Integrals and Derivatives: Theory and Applications, Gordon and Breach Science Publishers, Switzerland, 1993.

[30] A. Wintner, On the non-existence of conjugate points, Amer. J. Math. 73 (1951), 368-380.

[31] X. YANG AND K. LO, Liapunov-type inequality for a class of even-order differential equations, Appl. Math. Comput. 215 (2010), 3884-3890.

[32] X. YAnG, On Lyapunov inequality for certain higher-order differential equations, Appl. Math. Comput. 134 (2003), 307-317.

[33] X. YAnG, On inequalities of Lyapunov type, Appl. Math. Comput. 134 (2003), 293-300.

[34] Q. ZHANG AND X. HE, Liapunov-type inequalities for a class of even-order differential equations, J. Ineq. Appl. 2012, 2012:5. 